\title{
Odors can affect individuals' physiology and ethology - A study on ants as models
}

\author{
Marie-Claire Cammaerts ${ }^{1,2 *}$ and David Cammaerts ${ }^{3}$ \\ ${ }^{1}$ Independent Researcher (Rtd.), Biology of Organisms Department, University of Brussels, Belgium \\ 227, square du Castel Fleuri, 1170, Bruxelles, Belgium \\ ${ }^{3}$ Independent researcher, 13, Rue Silvela, 4900, Spa, Belgium
}

\begin{abstract}
Aiming to check if environmental artificially added odors can positively or negatively affect the individuals' health, we examined, using ants as model organisms, the effects of onion and of lavender odors on eleven ant's physiological and ethological traits. Onion odor increased the ants' linear and angular speed, as well as their aggressiveness against nestmates impacting thus their social relationship. It decreased their orientation ability, audacity, tactile perception, brood caring behavior, escaping ability, cognition as well as slightly their short term memory. On the contrary, lavender odor slightly increased the ants' linear speed, orientation ability, audacity, escaping ability, cognition and short-term memory. It did not affect their tactile perception, brood caring behavior and aggressiveness against nestmates (so, their social relationship). It slightly decreased their aggressiveness against aliens. Odors seem to have some effects on the ants individuals' physiological and behavior. Using ants as model organisms, and under the hypothesis that numerous physiological traits likely to be affected by aromatic molecules are similar in insect and humans, we can therefore emit the hypothesis that odors could be used to some extend to influence human physiology and behavior. This field of investigation, and the use of ants as model organisms, could be a way to investigate potential effects of active substances in aromatherapy, in which people are exposed to aromatic compounds through aerial diffusion or direct inhalation of these compounds.
\end{abstract}

\section{Introduction}

Aromatherapy is increasingly the subject of scientific research aiming to investigate the potential effects of active substances extracted as essential oils. It even becomes a field of the pharmaceutical research. It is thus relevant to question the potential effect of essential oils used through aerial diffusion, in order for instance to scent or to disinfect the environment. Essential oils are also increasingly used through direct inhalation, as decongestant or expectoration product, as well as compounds likely to produce psychological effects. This latter use rises the hypothesis of a potential effect of odors (= odorant compounds) on the individuals' physiology and ethology, apart from a simple repulsive or attractive response to them. If the effects of odors emitted by animals (i.e. pheromones) have been and are still currently deeply studied, and are thus rather well known, the influence of environmental odors on the animals' and the humans' behavior and psychology remain far less investigated.

For most but not all the researchers having worked on humans on this subject, there is an effective, scientifically proved, link between environmental odors and changes in humans' physiology and/or ethology. In a book devoted to the human sense of smell, Lawless [1] wrote a chapter on the effects of odors on mood and behavior. Such effects of odors occur via an impact on receptors located in precise brain zones [2]. In 2009, Herz wrote a review on the effect of odors on human. She scientifically analyzed 18 research publications showing effects of odors on mood, behavior and physiology, and concluded that a link effectively exists in most cases between environmental odors and the three here above cited traits [3]. Moss and co-authors have clearly shown the effects of two odors (oils of lavender and rosemary) on a few physiological humans' traits (cognitive performances and mood) [4]. Another evidence of the impact of odors on humans is the observation made by the dentist Lehrner: ambient odor of orange decreased the anxiety of female patients [5]. However, looking to the impact of stimulating and of smoothing smells on humans' heart rate and memory, Jackson found that the results were not statistically significant [6].

By design, the majority of scientific experimental works set up to investigate the effect of odors on humans are or could be potentially affected by some bias: (1) experimental subjects are aware that an environmental odor is experimentally added and are therefore likely to react in a somewhat different way than "treatment-naïve" ones; (2) an odor can be linked to a memorized previous event and induce through this memory some behavioral or even physiological reactions and (3) the potential link between odors and changes in any humans' traits is not always statistically valid. Therefore, it is relevant to study the potential effect of odors on the behavior of a model organism, for which we have already demonstrated some similarities in behavioral responses with those presented by humans [7-9]. We thus used ants as biological model and investigated the effect of two odors on their physiology, behavior and cognition. Our goals were therefore (i) to evaluate the potential use of ants as model organism in order to study effects of environmental odors, and (ii) to examine if, effectively, objectively, odors may have effects on animals' health.

${ }^{\star}$ Correspondence to: Marie-Claire Cammaerts, 27, square du Castel Fleuri 1170 Bruxelles, Belgium, Tel: 3226734969; E-mail: mccammaerts@gmail.com

Key words: aromatherapy, audacity, aggressiveness, cognition, locomotion, memory, tactile perception

Received: October 08, 2018; Accepted: October 25, 2018; Published: October 29, 2018 
We used two contrasted odors, that of onion and that of lavender (for the chemical composition of these odors: see the 'Material and Methods' section) which we set in the ants' environment (i.e. on their foraging area) after having made the control experiments. We used two colonies for studying the effects of onion odor, and two other ones collected the same day on the same site for studying the effects of lavender odor, to avoid that some onion odor still remained at the nest entrance and invalidated the observations made in presence of lavender odor. For the two controls, for the study of the effects of onion odor, and for the study of the lavender odor, each time, we assessed the ants' locomotion, orientation ability, audacity, tactile perception, brood caring behavior, aggressiveness towards nestmates, aggressiveness towards aliens, escaping behavior, cognition and memory. Here below, we explain why we used ants as models, which species we used and what we know on it. After that, we briefly relate our methods and detail our results. Then, we discuss our results and compare them to those of other researchers before concluding.

\section{Why using ants as models?}

The physiological traits of all the living organisms are fundamentally similar [10]. This is why they are generally firstly studied on animals used as models (e.g. fruit flies, cockroaches, bees, mice, monkeys), and thereafter on humans [11]. Insects, Hymenoptera among others, are often used as models because they develop rapidly and can easily be maintained in laboratories [12,13]. Ants could thus be used as models [7]. Indeed, these social insects present interesting evolved traits. They have, among others, some colonial regulation, labor division and they exchange information thanks to tactile and chemical signals (pheromones) [14-16]. They construct sophisticated nests, take care of their brood and queens, and chemically mark several zones of their habitat [14]. They can navigate, recruit congeners, clean their nest, relocate it, and manage cemeteries [15]. Due to such an evolved biology/ behavior, they could serve as model organisms for plenty of studies. The impact of products and situations, for instance, can be examined on them, and hypothesis of effects of such elements on other organisms can be emitted.

\section{Which species was used and what is known on it?}

We have largely studied the ants of the genus Myrmica, and collected information on, among others, their ecology, eyes morphology and angle of vision, visual perception, recruitment strategy, navigation system, learning [17], and the ontogenesis of some of their abilities [18]. Studying the effect of electromagnetic fields (EMF) on their learning, memory capabilities and responses to pheromones showed that they could be used as model organisms $[19,20]$. This was confirmed in the course of our studies on them of the potential harmful impact of many products used by humans $[8,9,21,22]$. Effects seen in ants were similar to those observed in humans, and other harmful effects, from which humans may suffer, were revealed. In the present work, we used again the ant $M$. sabuleti Meinert 1861 as insect models for revealing the consequences on physiological and ethological traits of added environmental odors. Doing so, we aimed to bring information about the potential effects of odor pollution (see the discussion section for explanations) on insects and other animals as well as on humans, and about the potential use of some odors for ameliorating the animals' and human beings' health.

\section{Material and methods}

\section{Collection and maintenance of ants}

The experiments were made on four colonies of M. sabuleti collected in June 2018, in an abandoned quarry located at Marchin (Belgium).
Two ones (labeled A and B) were used for the study of the effects of onion odor, and two other ones (labeled C and D) for the study of the effects of lavender odor (Figure 1). Indeed, after the achievement of the experiments relative to onion, some of its odor may be still present at the nest entrance, on the ants' cuticle, on the brood and in the wet cotton plug (see just below) located inside the nest. Other (similar) colonies were thus used for examining the impact of the lavender odor. A third colony, collected in the Aise valley (Ardenne, Belgium) in September 2018, furnished the aliens used during the experiment examining the ants' aggressiveness against aliens. Each colony was maintained, as previously [18-21], in two glass tubes half filled with water, a cotton plug separating the ants from the water. The nest tubes of each colony were deposited in a tray $(34 \times 23 \times 4 \mathrm{~cm})$, and the ants were fed with Tenebrio molitor larvae (Linnaeus, 1758) delivered three times per week, and sugar water provided ad libitum in cotton plugged tubes. The ambient temperature was $c a 20^{\circ} \mathrm{C}$, the air humidity $80 \%$, the lighting 330 lux, and the electromagnetism surrounding field $2 \mu \mathrm{Wm}^{2}$. These conditions were optimum for the species. The ants of the same colony are here often named 'nestmates'.

\section{Odors employed}

As already mentioned in the introduction section, we used two different kinds of odors, that of onion (Allium cepa) and that of lavender (Lavandula angustifolia).

Onion cells contain 1-propenyl-L-cystein-sulfoxide in their cytoplasm and the enzyme allinase in their vacuome. When cut (as in our experimental work, or when damaged in nature by animals), several substances are generated, among others 1-propenylsulphenic acid. The latter substance partly becomes by itself thiosulfinate, and is partly transformed into propanethial-S-oxyde due to the action of the lachrymal factor synthase. These substances act as feeding repellents for herbivores [23-25]. Such substances could potentially interact with chemical receptors on ants' antenna and therefore produce effects on some behavioral and/or physiological traits. In the present work, we simply deposited 16 pieces of onion (about $1 \mathrm{~cm}^{3}$ ) on the colonies A and B's foraging area, between the nest entrances and the food sites (Figure 1). These pieces were refreshed each two days.
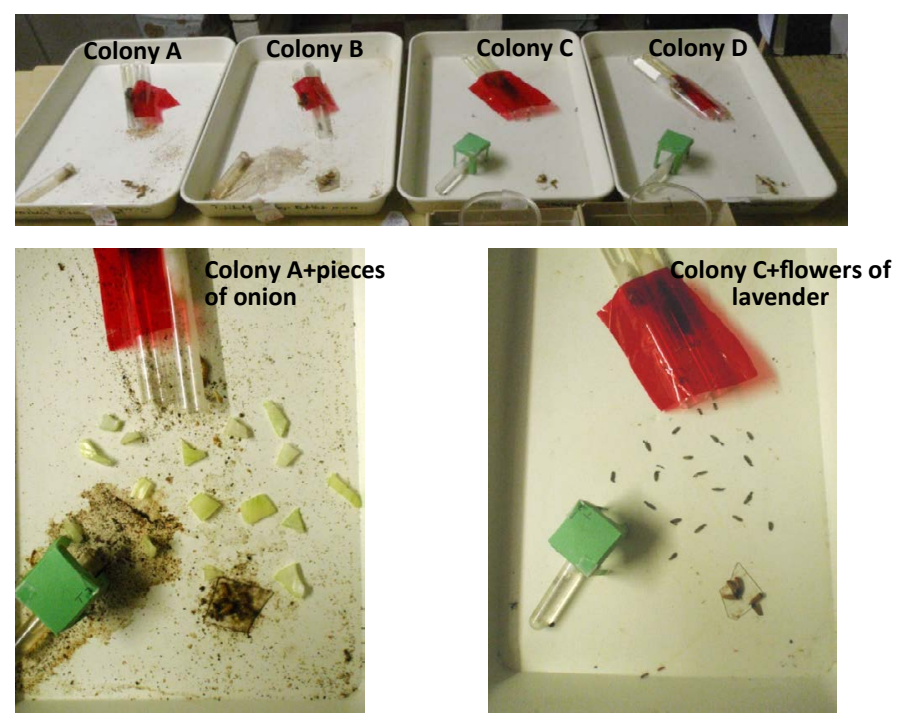

Figure 1. The four used colonies (upper photo), and the setting of the two kinds of odor the effects of which were here examined: onion on colonies A and B (lower left photo), lavender on colonies $\mathrm{C}$ and $\mathrm{D}$ (lower right photo) 
Flowers of Lavendula augustifolia emit odorous volatile compounds, among which ethylamylceton is the most responsible compound for the pleasant odor of lavender [26-28]. Together with the largely used lavender essential oil [https://www.ema.europa.eu/medicines/herbal/ lavandulae-aetheroleum, https://www.ema.europa.eu/medicines/ herbal/lavandulae-flos] (which is a very high concentration of the lavender odor we did not use), the lavender flowers (which we here used) are also commonly employ at home to scent the air, the clothes, the bathwater for instance. Such a perfume may impact the humans' mood (see the introduction section: [4]). In the present work, we simply deposited 16 lavender flowers on the colonies $C$ and D's foraging area, between the nest entrances and the food sites (Figure 1). Lavender flowers keep their odor during a very long time period, i.e. more than one year. However, they were renewed each two days since the ants may deposit on them their species' area foraging odor [14].

\section{Experimental planning}

Readers are invited to look to Table 1 for easier understanding the following subsections, including those of the results section.

\section{Examined ants' traits}

Locomotion and orientation ability: These traits were quantified on ants moving in their tray, their linear and angular speeds without presenting them any stimulus, their orientation while stimulating them with a nestmate tied to a piece of paper (Figures 2A1,2A2,3A1,3A2). Such a tied nestmate emits its attractive mandibular glands alarm pheromone. As previously $[8,9,21,22]$, for the ants' speeds and for their orientation, the trajectory of 40 workers was recorded and analyzed thanks to appropriate software [29]. The linear speed (in $\mathrm{mm} / \mathrm{s}$ ) was the length of a trajectory divided by the time spent to travel it, the angular speed (in angular degree $/ \mathrm{cm}=$ ang.deg. $/ \mathrm{cm}$ ) was the sum of the angles made by successive adjacent segments, divided by the length of the trajectory, and the orientation (in ang. deg.) towards a location was the sum of the successive angles made by the direction of the trajectory and that towards the location, divided by the number of measured angles. When the angle value obtained was lower than $90^{\circ}$, the animal tended to orient itself towards the location; when the value was larger than $90^{\circ}$, the animal tended to avoid the location. The median and quartiles of each distribution of 40 values were established.

Audacity: As in previous studies [8,9,21,22], a cylindrical tower (height $=4 \mathrm{~cm}$; diameter $=1.5 \mathrm{~cm}$ ) tied to a squared platform $\left(9 \mathrm{~cm}^{2}\right)$, made of white Steinbach ${ }^{\circledR}$ paper, was deposited in the ants' tray, and those present on this apparatus were counted 10 times over $10 \mathrm{~min}$ (Figures 2B1,2B2,3B1,3B2). The mean and the extremes of the counts were established, and the counts obtained for the two colonies and for two successive minutes were added for statistical analysis.

Tactile perception: When ants perceive the uncomfortable character of a rough substrate, they walk on it with difficulties, slowly and sinuously. When they weakly perceive such an uncomfortable character, they move more quickly and less sinuously. Consequently, to assess the ants' tactile perception, the ants' locomotion on a rough substrate was analyzed (as usually, see above the section 'Locomotion'). As in previous works $[8,9,21,22]$, a folded piece $(3 \times(2+7+2=11) \mathrm{cm})$ of emery paper $n^{\circ} 280$ paper was tied to the bottom and the borders of a tray $(15 \times 7 \times 4.5 \mathrm{~cm})$, dividing so this tray into a first zone $3 \mathrm{~cm}$ long, a second one $3 \mathrm{~cm}$ long where was the emery paper, and a last one $9 \mathrm{~cm}$ long. Such an apparatus was built for each colony. To make an experiment, 12 ants of each colony were transferred into the first zone of their apparatus, and the trajectory of 24 ants was recorded when they walked on the rough substrate (Figures $2 \mathrm{C} 1,2 \mathrm{C} 2,3 \mathrm{C} 1,3 \mathrm{C} 2$ ). The ants' linear and angular speeds were then assessed as usually (see above, the section 'Locomotion').

Brood caring behavior: A few larvae and/or nymphs of each colony were removed from the nest and were set in front of the entrance. Five of these larvae or nymphs, as well as the ants' behavior towards them, were observed (Figures 2D1,2D2,3D1,3D2) and the larvae or nymphs among these $5+5=10$ not yet replaced in the nest after $5 \mathrm{~s}, 2,4,6,8$, and 10 min were counted.

Aggressiveness against nestmates and against aliens: As in previous works $[8,9,21,22]$, these traits were assessed, for each colony, during five dyadic encounters between an observed ant and either a nestmate or an alien ant. Each encounter occurred in a cylindrical cup (diameter $=2.5 \mathrm{~cm}$, height $=1.8 \mathrm{~cm}$ ), and the behavior of the observed ant was characterized by the number of times it did nothing (level 0 of aggressiveness), contacted the opponent with its antennae (level 1), opened its mandibles (level 2), gripped the other ant (level 3), tried to sting or stung the opponent (level 4) (Figures 2E1,2E2,2F1,2F2,3E1,3E $2,3 \mathrm{~F} 1,3 \mathrm{~F} 2$ ). The numbers obtained for the two colonies were added. As in previous works [18-21], the ants' aggressiveness was also assessed by the variable " $\mathrm{a}$ "=number of aggressiveness levels $2+3+4 /$ number of levels $0+1$.

Escaping behavior: As in previous works [8,9,21,22], for each colony, 6 ants were enclosed under a reversed polyacetate glass $(h=8$

Table 1. Synopsis of the work. The order according to which the experimental work has been made on one hand, and the paper is presented on the other hand differs. Two ant colonies had to be used for each two studied odors. The here below synopsis may help the readers to understand all this, i.e., the performance of the experiments and the writing of the paper

\begin{tabular}{|c|c|}
\hline Experimental planning & Presentation of the work \\
\hline $\begin{array}{l}\text { Collection of } 4 \text { colonies in May } 2018 \\
\text { Maintenance of the } 4 \text { colonies (A, B, C, D) }\end{array}$ & Introduction \\
\hline $\begin{array}{l}\text { Control experiments } 1 \text { on colonies A and B } \\
\text { (locomotion, orientation, audacity, tactile perception, brood caring, aggressiveness, } \\
\text { escaping, cognition, memory) } \\
\text { Setting onion odor on colonies A and B } \\
\text { Test experiments on colonies A and B }\end{array}$ & $\begin{array}{l}\text { Material and Methods } \\
\text { Collection and maintenance of ants } \\
\text { Odors added .... Figure } 1 \\
\text { Table } 1 \\
\text { Examined traits: locomotion, ...memory }\end{array}$ \\
\hline $\begin{array}{l}\text { (first memory, then locomotion ....cognition) } \\
\text { Control experiments } 2 \text { on colonies C and D } \\
\text { (locomotion, orientation, audacity, tactile perception, brood caring, aggressiveness, } \\
\text { escaping, cognition, memory) } \\
\text { Setting lavender odor on colonies C and D }\end{array}$ & $\begin{array}{l}\text { Results } \\
\text { Onion odor Table 2, Figure } 2 \\
\text { locomotion ... memory } \\
\text { Lavender odor Table 3, Figure } 3 \\
\text { locomotion ... memory }\end{array}$ \\
\hline $\begin{array}{l}\text { Test experiments on colonies } \mathrm{C} \text { and } \mathrm{D} \\
\text { (first memory, then locomotion ....cognition) }\end{array}$ & Discussion/Conclusion \\
\hline Bibliographical research & References \\
\hline
\end{tabular}


$\mathrm{cm}$, bottom diameter $=7 \mathrm{~cm}$, ceiling diameter $=5 \mathrm{~cm}$ ) set in the ants' foraging area. That glass had a notch ( $3 \mathrm{~mm}$ height, $2 \mathrm{~mm}$ broad) in its bottom rim to allow the ants escaping (Figures 2G1,2G2,3G1,3G2). Thirty seconds, 2, 4, 6, 8, 10 and 12 min after the ants had been enclosed, the escaped ants and those still under the glass were counted. The results obtained for the two colonies were added. The ants' ability in escaping was also quantified by the variable ' $n$ ' of ants escaped after 12 $\mathrm{min} / 12$ '. Such ability is reduced when the ants' stress and/or cognition are impacted.

Cognition: We used again the experimental protocol set up when studying the effects of nicotine [30]. For each colony, two pieces of white paper $($ Steinbach $\AA, 12 \times 4.5 \mathrm{~cm})$ duly folded were inserted in a tray $(15 \times 7 \times 4.5 \mathrm{~cm})$, dividing the tray into a first small zone, a zone with twists and turns, and a large zone into which a piece of wet cotton had been placed (Figures $2 \mathrm{H} 1,2 \mathrm{H} 2,3 \mathrm{H} 1,3 \mathrm{H} 2$ ). To make an experiment, 15 ants of each colony were transferred into the first zone of their apparatus, and those present in this zone and in the large one were counted after $30 \mathrm{~s}, 2,4,6,8,10$ and $12 \mathrm{~min}$. The numbers obtained for the two colonies were added.

Memory: In a first time, under control conditions, a green hollow cube was set above the entrance of the sugar water tube of the two colonies, and the ants went so through visual conditioning. Their acquisition of such a conditioning was checked by making tests over time until their conditioning score no longer increased. To make a test, 10 ants of colony A (or C) and of colony B (or D) were individually tested in a Y-apparatus provided with a green hollow cube in one of its branch. The Y-apparatus was made of strong white paper and was deposited in a tray $(30 \times 15 \times 4 \mathrm{~cm})$. The green cube was randomly located in the right or the left branch of this Y-apparatus. Moving into the branch containing the cue was considered as giving the correct response (Figures 2I1,2I2,3I1,3I2). Each test provided the response of 20 ants, and from them, the proportion of correct responses. After the ants were duly conditioned, either pieces of onion or lavender flowers were set on the foraging area of colonies $\mathrm{A}$ and $\mathrm{B}$ or colonies $\mathrm{C}$ and $\mathrm{D}$ respectively, and 24 hours later, tests in Y-apparatus were made to assessed the ants' conditioning score, and through this score, their short term memory. In other words, the proportion of correct responses was determined for each used odor, i.e. onion on colonies A and B, lavender on colonies $\mathrm{C}$ and $\mathrm{D}$. The ants' short term memory in presence of one or the other used added odor was thus examined in priority, before assessing the other traits. It must be done in this order because, if the memory would have been examined later, the ants would have forgotten the association between the green cube (CS) and the sugar water (US).

\section{Statistical analysis}

The numerical results concerning the ants' linear speed, angular speed, orientation, tactile perception, aggressiveness against nestmates and against aliens, as well as memory were ranked, and those obtained in presence of an added odor were statistically compared to those obtained under control condition using the non-parametric $\chi^{2}$ test [31]. As for the ants' audacity, brood caring, escaping behavior and
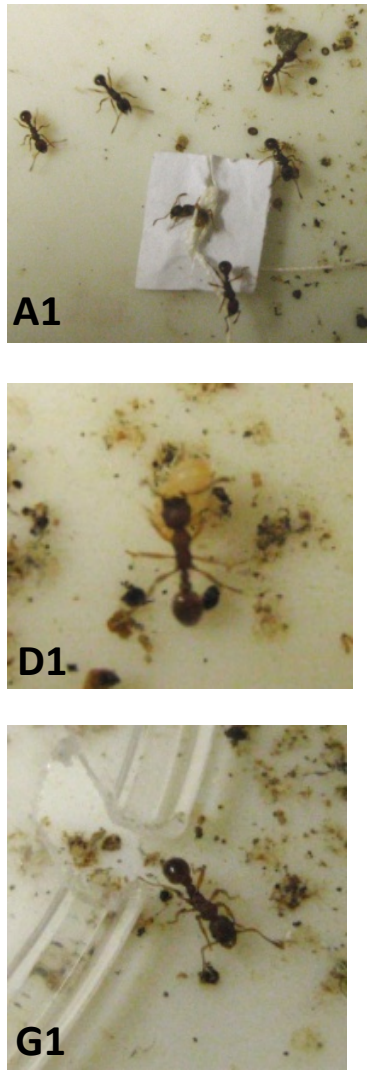
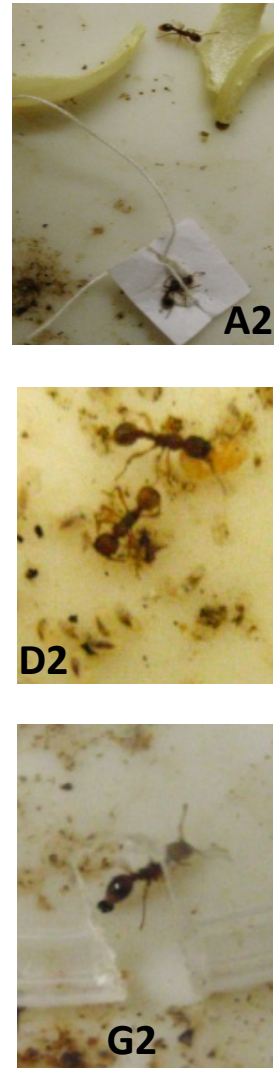
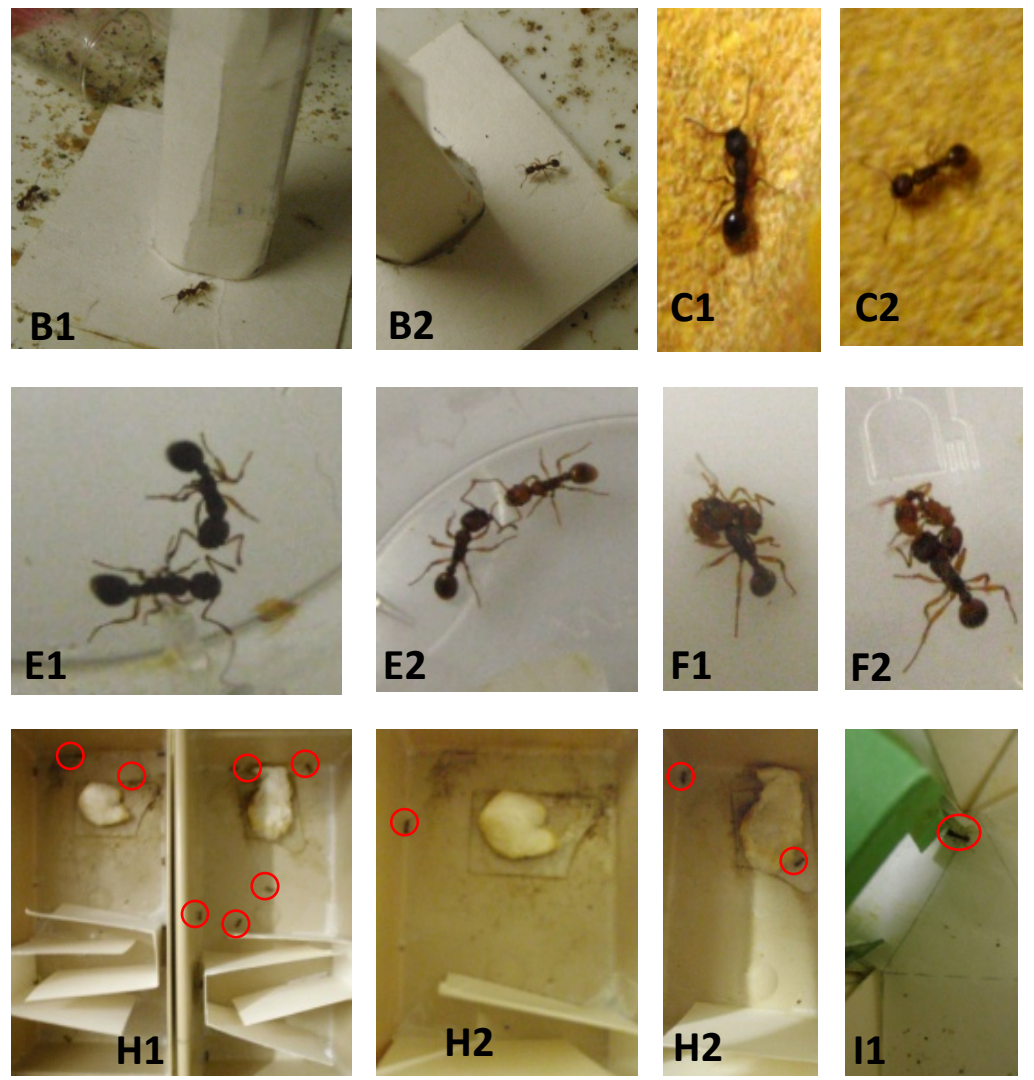

Figure 2. Some views of the experiments relative to onion odor. 1: Control experiments, without odor; 2: Test experiments, with onion odor; A: Ants coming towards a tied nestmate and doing so poorly under onion odor; B: Ants coming onto an unknown apparatus; C: Ants moving on a rough substrate with difficulty under normal condition, and easier under onion odor (its perception being reduced); D: Ants taking care of their brood and doing so badly under onion odor (i.e. an ant staying among several larvae without taking care of them); E: Two nestmates not at all aggressive under normal condition, and slightly aggressive under onion odor; F: An ant aggressing an alien; G: An ant escaping from an enclosure under control condition, and not escaping under onion odor; $\mathbf{H}$ : Seven ants (red circles) under control condition and three ants (red circles) under onion odor having crossed a twist and turns path; I: An ant (red circle) trained to a hollow green cube giving the correct response during a test in a Y-apparatus provided with this cue in one of its branches 
cognition, the comparison was statistically evaluated using the nonparametric test of Wilcoxon [31].

\section{Results}

\section{Onion odor}

Locomotion: Under onion odor, the ants walked at a linear speed slightly higher than that presented under control situation (11.6 vs 10.8 $\left.\mathrm{mm} / \mathrm{sec} ; \chi^{2}=8.27, \mathrm{df}=2,0.01<\mathrm{P}<0.02\right)$ and at a largely higher sinuosity (174 vs 112 ang. deg./cm; $\chi^{2}=52.50, \mathrm{df}=2, \mathrm{P}<0.001$ ) (Table 2). The ants' large sinuosity under onion odor was obvious to the observer. That odor impacted thus the ants' movement, and maybe also their nervousness and stress level.

Orientation ability: This trait was affected by onion odor (Table 2) (Figures $2 \mathrm{~A} 1$ and $2 \mathrm{~A} 2$ ). While under normal condition, the ants well moved towards a tied nestmate (43.2 ang. deg.), they did so poorly under onion odor (68.4 ang. deg.), the difference of orientation ability between ants reacting under the two kinds of condition being statistically significant $\left(\chi^{2}=18.62, \mathrm{df}=2, \mathrm{P}<0.001\right)$. The ants were obviously perturbed by the onion odor, and less perceived and/or less reacted to the attractive alarm pheromone emitted by the tied nestmate.

Audacity: Unexpectedly, this trait was affected by onion odor (Table 2) (Figures 2B1 and 2B2). While under normal situation, meanly 1.50 ants were seen on the unknown apparatus, in presence of onion odor, only 1.15 ants were meanly seen on it. This difference of audacity between the ants tested under normal situation and under onion odor was at the limit of significance $(\mathrm{N}=4, \mathrm{~T}=10, \mathrm{P}=0.063)$. Onion odor affected thus the ants' usual behavior in a new environment.

Tactile perception: Onion odor impacted this physiological trait (Table 2) (Figures $2 \mathrm{C} 1$ and 2C2). Under normal situation, the ants moved very slowly and sinuously on a rough substrate $(5.1 \mathrm{~mm} / \mathrm{sec}$, 308 ang. deg. $/ \mathrm{cm})$, perceiving well the uncomfortable character of the substrate. Under onion odor, the ants walked on such a substrate not so slowly and sinuously $(9.6 \mathrm{~mm} / \mathrm{sec}, 146$ ang.deg. $/ \mathrm{cm})$, perceiving thus less well the uncomfortable character of the substrate. The difference of locomotion on a rough substrate between ants tested under normal and under onion odor conditions was significant (linear speed: $\chi^{2}=30.13$, $\mathrm{df}=1, \mathrm{P}<0.001$; angular speed: $\left.\chi^{2}=34.28, \mathrm{df}=1, \mathrm{P}<0.001\right)$.

Table 2. Impact of onion odor on eleven ants' physiological or ethological traits. Experimental, numerical and statistical details are given in the text. Briefly, onion odor increased the ants' speed of locomotion and aggressiveness against nestmates, and decreased their orientation ability, audacity, tactile perception, brood caring behavior, escaping ability, cognition as well as slightly their short-term memory. Some (aggressive, unpleasant) odors may thus impact the individuals' physiology and behavior $(\mathbf{m m} / \mathbf{s e c}$ : Millimeter per second; ang.deg./cm: Angular degree per centimeter; ang.deg.: Angular degree; $\mathbf{n}^{\circ}$ : Number; $\mathbf{a}$ : Variable (with no unit) assessing the ants' aggressiveness)

\begin{tabular}{|l|c|c|}
\hline \multicolumn{1}{|c|}{ Traits } & Control 1 & Onion odor \\
\hline Linear speed (mm/sec) & $10.8(10.1-11.6)$ & $11.6(10.1-12.8)$ \\
\hline Angular speed (ang.deg./cm) & $112(88-134)$ & $174(164-197)$ \\
\hline Orientation (ang.deg) & $43.2(35.2-54.1)$ & $68.4(49.9-93.1)$ \\
\hline Audacity $\left(\mathrm{n}^{\circ}\right)$ & $1.50[0-3]$ & $1.15[0-2]$ \\
\hline Tactile perception: & $5.1(4.5-5.5)$ & $9.6(8.5-11.2)$ \\
Linear speed & $308(264-329)$ & $146(132-167)$ \\
Angular speed & 0 & 4 \\
\hline Brood caring $\left(\mathrm{n}^{\circ} / 10\right)$ & 0.15 & 1.01 \\
\hline Aggressiveness: & 3.03 & 4.21 \\
\hline Against nestmates $(\mathrm{a})$ & $10 / 12=0.83$ & $7 / 12=0.58$ \\
Against aliens $(\mathrm{a})$ & 7 & 11 \\
\hline Escape behavior $\left(\mathrm{n}^{\circ} / \mathrm{n}^{\circ}\right)$ & 7 & 3 \\
\hline Cognition: Small area $\left(\mathrm{n}^{\circ}\right)$ & $90 \%$ & $70 \%$ \\
\hline Large area $\left(\mathrm{n}^{\circ}\right)$ & & \\
\hline Short term memory & & \\
\hline
\end{tabular}

Brood caring behavior: This social behavior was impacted by onion odor (Table 2) (Figures 2D1 and 2D2). Under normal condition, the ants rapidly re-entered the larvae and nymphs experimentally removed from the nest. After the 10 experimental minutes, none of the observed larvae and nymphs was still out of the nest. Under onion odor, the ants did so badly, with delay and hesitation, and 4 of the observed larvae and nymphs were still out of the nest after the 10 experimental minutes. The difference of counted numbers of larvae and nymphs between ants tested under the two kinds of situation was significant: $\mathrm{N}=5, \mathrm{~T}=+15$, $\mathrm{P}=0.031$. Since onion odor affected the ants' behavior in front of their brood, this odor might also affect other ants' social relationship, a hypothesis we later submitted to experimentation (see below).

Aggressiveness against nestmates: This social behavior was impacted by onion odor (Table 2) (Figures 2E1 and 2E2). Under normal condition, ants presented 61 levels 0 of aggressiveness, 74 levels 1, 21 levels 2 and 0 levels 3 and 4; their "aggressiveness" variable equaled 0.15 . Under onion odor, the ants presented 23 levels 0 of aggressiveness, 46 levels 1, 65 levels 2, 1 level 3 and 4 levels 4; their 'aggressiveness" variable equaled 1.01. The difference of level numbers between ants experimented without and with onion odor was significant: $\chi^{2}=50.34$, $\mathrm{df}=3, \mathrm{P}<0.001$. Onion odor impacted thus the ants' social relationship, a result in agreement with that relative to the ants' brood caring behavior (see above), what may affect the colony survival.

Aggressiveness against aliens: This trait was not affected by onion odor (Table 2) (Figures 2F1 and 2F2). When tested in front of an alien, in the absence as well as in the presence of onion odor, an ant always became aggressive towards the opponent. Under control condition, the ants presented 7 levels 0, 25 levels 1, 41 levels 2, 29 levels 3, and 27 levels 4. Under onion odor, they presented 5 levels 0,23 levels 1, 38 levels 2 , 56 level 3 and 34 levels 4 . The difference between these two series of numbers was not significant: $\chi^{2}=7.53, \mathrm{df}=4,0.10<\mathrm{P}<0.20$. The variable assessing the ants' aggressiveness equaled 3.03 under control condition, and 4.21 under onion odor. The latter odor increased thus the ants' aggressiveness against aliens, but this increase was not statistically significant because the ants were already very aggressive without the odor.

Escaping behavior: Onion odor impacted this trait (Table 2) (Figures 2G1 and 2G2). Under normal condition, the numbers of ants escaped after 30 seconds, 2, 4, 6, 8, 10 and 12 minutes equaled 0, 2, 4, 6, 6,8 , and 10 respectively. The variable assessing this escaping behavior equaled $10 / 12=0.93$. Under onion odor, the numbers of ants escaped after the same time periods equaled $0,1,2,2,4,5$, and 7 respectively, the variable assessing this escaping behavior equaling $7 / 12=0.58$. The difference of escaping performance between ants tested under normal and onion odor conditions was statistically significant: $\mathrm{N}=6, \mathrm{~T}=-21$, $\mathrm{P}=0.016$. This was very probably due to the ants' stronger state of stress while being under onion odor since this 'escaping' behavior is usually devoted to the assessment of the ants' state of stress [25,26]. However, this may also result from some decrease of the ants' cognition when staying under onion odor. The following experiment examined this hypothesis (see below).

Cognition: This physiological trait was slightly affected by onion odor (Table 2) (Figures $2 \mathrm{H} 1$ and 2H2). Under normal condition, the numbers of ants still present in the small area (in front of the twists and turns path) equaled $23,19,15,13,12,9$ and 7 after 30 seconds, 2, 4, 6, 8,10 and 12 minutes respectively, while those having reached the large area beyond the difficult path equaled $0,1,1,2,4,6$, and 7 respectively. Under onion odor, these numbers equaled $23,18,16,14,13,11$, and 11 for the ants still present in the first, small area, and $0,1,1,2,3,3$, and 3 
for those having reached the large area. The difference of ants' ability in crossing the twists and turns path between those living under normal condition on one hand and under onion odor on the other hand was at the limit of significance (small area: $\mathrm{N}=6, \mathrm{~T}=+18.5, \mathrm{P}=0.062$; large area: $\mathrm{N}=3$, NS due to the smallness of the sample). Consequently, on the basis of this result and of the just previous one (see above), it can be deduced that onion odor slightly decreased the ants' cognitive abilities and largely increased their state of stress. Another experiment, related here below, examined the impact of onion on the ants' short-term memory (through their conditioning score), what is a physiological trait linked to cognition.

Short term memory: Before examining the impact of onion odor on the ants' short-term memory, the ants of colonies A and B were trained (conditioned) to a hollow green cube and their conditioning acquisition assessed. These ants presented a conditioning score of $80 \%$, $85 \%, 90 \%$ and again $90 \%$ after $24,48,55$ and 72 hours respectively. Thus, their final conditioning score equaled $90 \%$. At that time, pieces of onion were set on the ants' foraging area, and (see the Material and Methods section) the first experiment made on ants under onion odor (the green cube being still above the sugar water tube entrance) was the assessment of their conditioning score, thus of their short-term memory (Table 2) (Figures 2I1 and 2I2). This conditioning score equaled $70 \%$ what is lower than $90 \%$, the score just previously presented under normal condition. However, the difference between the ants' response without odor (18 correct responses and 2 wrong ones) and that under onion odor (14 correct responses and 6 wrong ones) was not statistically significant $\left(\chi^{2}=1.41, \mathrm{df}=1,0.20<\mathrm{P}<0.30\right)$. Consequently, onion odor only slightly affected the ants' short-term memory (as it slightly affected their cognitive abilities, see above).

\section{Lavender odor}

Locomotion: The ants' locomotion was slightly changed by lavender odor: in fact, the ants walked simply somewhat more rapidly (Table 3). The difference of linear speed between ants moving under control condition and ants moving under lavender odor was slightly statistically significant $\left(\chi^{2}=9.91, \mathrm{df}=3,0.01<\mathrm{P}<0.02\right)$, while the difference of angular speed between the ants moving under these two different conditions was not significant $\left(\chi^{2}=0.51, \mathrm{df}=3,0.90<\mathrm{P}<0.95\right)$. To the observer, all happened as if ants had a larger tendency to forage while living under lavender odor.

Orientation ability: This ability was slightly improved by lavender odor (Table 3) (Figures 3A1 and 3A2). Under normal condition as well as under lavender odor, the ants oriented themselves very well towards a tied nestmates, but they did so somewhat better in the presence of the lavender odor. The difference of orientation ability between the ants tested under the two kinds of condition was at the limit of significance $\left(\chi^{2}=4.72, \mathrm{df}=2,0.05<\mathrm{P}<0.10\right)$. This result allowed also presuming that lavender odor did not affect the ants' sensitive perception, at least their olfactory one. A further experiment examined if the ants' tactile perception was impacted by lavender odor (see below).

Audacity: This ethological trait was unexpectedly affected by lavender odor. It was in fact rather increased (Table 3) (Figures 3B1 and $3 \mathrm{~B} 2$ ), and this was at the limit of significance (due to the smallness of the sample) $(\mathrm{N}=4, \mathrm{~T}=10, \mathrm{P}=0.063)$. This result was in agreement with the previously observed increase of foraging tendency under lavender odor (see above).

Tactile perception: The ants' tactile perception was not at all affected by lavender odor (Table 3) (Figures 3C1 and 3C2). Under normal condition, the ants moved very slowly and sinuously on a
Table 3. Impact of lavender odor on eleven ants' physiological or ethological traits. Experimental, numerical and statistical details are given in the text. Briefly, lavender odor slightly increased the ants' linear speed of locomotion, orientation ability, audacity, escaping ability, cognition and short-term memory. It did not affect their tactile perception, brood caring behavior and aggressiveness against nestmates. It slightly decreased aggressiveness against aliens. Some (smooth, pleasant) odors may thus favorably affect the individuals' physiology and behavior (mm/sec: Millimeter per second; ang.deg./cm: Angular degree per centimeter; ang.deg.: Angular degree; $\mathbf{n}^{\circ}$ : Number; a: Variable (with no unit) assessing the ants' aggressiveness)

\begin{tabular}{|l|c|c|}
\hline \multicolumn{1}{|c|}{ Traits } & Control 2 & Lavender odor \\
\hline Linear speed (mm/sec) & $11.6(10.0-12.5)$ & $12.7(11.6-14.2)$ \\
\hline Angular speed (ang.deg./cm) & $118(100-137)$ & $119(99-131)$ \\
\hline Orientation (ang.deg) & $40.7(29.5-50.8)$ & $28.5(22.5-41.6)$ \\
\hline Audacity $\left(\mathrm{n}^{\circ}\right)$ & $2.20[0-3]$ & $3.05[1-6]$ \\
\hline Tactile perception: & $5.7(4.9-6.6)$ & $5.6(4.8-6.5)$ \\
Linear speed & $245(224-292)$ & $241(222-265)$ \\
\hline Angular speed & 0 & 0 \\
\hline Brood caring $\left(\mathrm{n}^{\circ} / 10\right)$ & 0.13 & 0.13 \\
\hline Aggressiveness: & 3.47 & 2.92 \\
\hline Against nestmates $(\mathrm{a})$ & $9 / 12=0.75$ & $12 / 12=1.00$ \\
Against aliens $(\mathrm{a})$ & 12 & 6 \\
\hline Escape behavior $\left(\mathrm{n}^{\circ} / \mathrm{n}^{\circ}\right)$ & 5 & $100 \%$ \\
\hline Cognition: First area $\left(\mathrm{n}^{\circ}\right)$ & $85 \%$ & \\
\hline Last area $\left(\mathrm{n}^{\circ}\right)$ & & \\
\hline Short term memory & &
\end{tabular}

rough substrate $(5.7 \mathrm{~mm} / \mathrm{s}, 245 \mathrm{ang} . \mathrm{deg} . / \mathrm{cm})$, and they did so also under lavender odor, presenting then nearly exactly the same linear and angular speed $(5.6 \mathrm{~mm} / \mathrm{s} ; 241$ ang.deg./ $/ \mathrm{cm})$. There was thus no statistical difference between the ants' locomotion on a rough substrate, the ants being under normal condition or under lavender odor (linear speed: $\chi^{2}=0.08, \mathrm{df}=1,0.70<\mathrm{P}<0.80$; angular speed: $\chi^{2}=3.05, \mathrm{df}=3$, $0.30<\mathrm{P}<0.50)$.

Brood caring behavior: This social ethological trait was not impacted by lavender odor (Table 3) (Figures 3D1 and 3D2), on the contrary. Under normal condition as well as under lavender odor, the ants took care of their brood, and nearly immediately hold the larvae or nymphs experimentally removed from the nest, and then tempted to replace them in the nest. Under lavender odor, the ants did so somewhat more quickly. The numbers of larvae still remaining on the foraging area after 30 seconds, 2, 4, 6, 8 and 10 minutes equaled 10, $8,6,4,2$ and 0 respectively under normal condition, and 10, 8, 5, 4, 1 and 0 respectively under lavender odor. Of course, the difference of brood caring behavior between the ants tested under the two kinds of condition was not significant ( $\mathrm{N}=2$, NS). As a matter of fact, it can be presumed that the lavender odor did not at all affect the ants' social relationship, a presumption examined in the following experiment (see below).

Aggressiveness against nestmates: Lavender did not at all impact this social behavioral trait (Table 3) (Figures 3E1 and 3E2). The numbers of ants presenting the levels $0,1,2,3$ and 4 of aggressiveness in front of a nestmate equaled $46,58,14,0$ and 0 respectively under normal condition, as well as 53,52, 14, 0 and 0 respectively under lavender odor. The difference of behavior towards nestmates between ants living under the two kinds of condition (normal or with lavender odor) was not at all significant $\left(\chi^{2}=0.80, \mathrm{df}=2,0.50<\mathrm{P}<0.70\right)$, and was in fact null.

Aggressiveness against aliens: Briefly, lavender very slightly and not statistically affected this trait (Table 3) (Figures 3F1 and 3F2). Under normal condition, the numbers of ants presenting the levels 0 , $1,2,3$ and 4 of aggressiveness against an alien equaled 9, 29, 51, 51 and 30 respectively. Under lavender odor, these numbers (obtained without remembering the control ones) equaled 9, 29,51, 46 and 14 respectively. 
Of course, the difference between the ants' numbers recorded under the two kinds of situation was not significant $\left(\chi^{2}=4.57, \mathrm{df}=4,0.30<\mathrm{P}<0.50\right)$. However, on the basis of the observation of the reacting ants and of the obtained numerical results, it could be noted that, under lavender odor, the ants were less inclined in attacking the alien and were often gripped and stung themselves before having been able to grip and to sting by themselves the opponent. This difference of behavior caused by the lavender odor reflected a somewhat lower consciousness of the potential presence of a danger, what was in agreement with the previously observed ants' larger audacity in front of an unknown apparatus (see above).

Escaping behavior: This trait was unexpectedly enhanced by lavender odor (Table 3) (Figures 3G1 and 3G2). Under normal condition, $0,1,3,5,6,7$ and 9 ants could escape from the enclosure after 30 seconds, 2, 4, 6, 8, 10 and 12 minutes respectively. The variable assessing this escaping behavior equaled $9 / 12=0.75$. Under lavender odor, these numbers of escaped ants after the same time periods equaled $0,2,4,6,8,10$ and 12 respectively. The variable assessing this escaping behavior equaled $12 / 12=1.00$, and the difference between the 7 counted numbers of escaped ants under normal and lavender odor conditions was significant $(\mathrm{N}=6, \mathrm{~T}=21, \mathrm{P}=0.016)$. Under lavender odor, the ants well and quickly walked essentially along the rim of the enclosure and so found the exit (the notch) in short times. The present experiment was primarily set up for evaluating the ants' state of stress [32,33]: the more stressed are the ants, the less able are they in escaping. It can thus be gathered that lavender odor did not at all stress the ants, on the contrary. The escaping behavior depends also from the individuals' cognition. It can thus also be inferred that lavender odor did not decrease the ants' cognition and may even somewhat enhance it. The following experiment allowed examining this presumption (see below).

Cognition: This trait appeared to be enhanced by lavender odor (Table 3) (Figures $3 \mathrm{H} 1$ and $3 \mathrm{H} 2$ ). Under normal condition, the numbers of ants still present in the area in front of the twists and turns path equaled $30,18,15,15,13,12$ and 12 after 30 seconds, 2, 4, 6, 8, 10 and 12 minutes respectively, while those having reached the large area beyond the difficult path equaled $0,0,0,2,3,4$ and 5 after the same time periods. Under lavender odor, these numbers of ants equaled 30, 15, $12,11,7,7$ and 6 for the first area, and $0,0,2,3,5,6$ and 8 for the last area. The difference of behavior (which depended at least partly from cognition) between the ants experimented under normal and lavender odor conditions was significant (first area: $\mathrm{N}=6, \mathrm{~T}=-21, \mathrm{P}=0.016$; last large area: $\mathrm{N}=5, \mathrm{~T}=15, \mathrm{P}=0.031$ ). This result was in agreement with the previous one relative to the ants' escaping behavior, as well as with the observed larger ants' foraging behavior and audacity (see above).

Short term memory: Under normal condition, the ants presented a score of $70 \%, 80 \%, 85 \%, 90 \%, 85 \%$ and $85 \%$ after $7,24,31,48,55$, and 72 hours respectively. Their final score equaled thus $85 \%$. Let us recall that this experiment was the first one made under lavender odor.
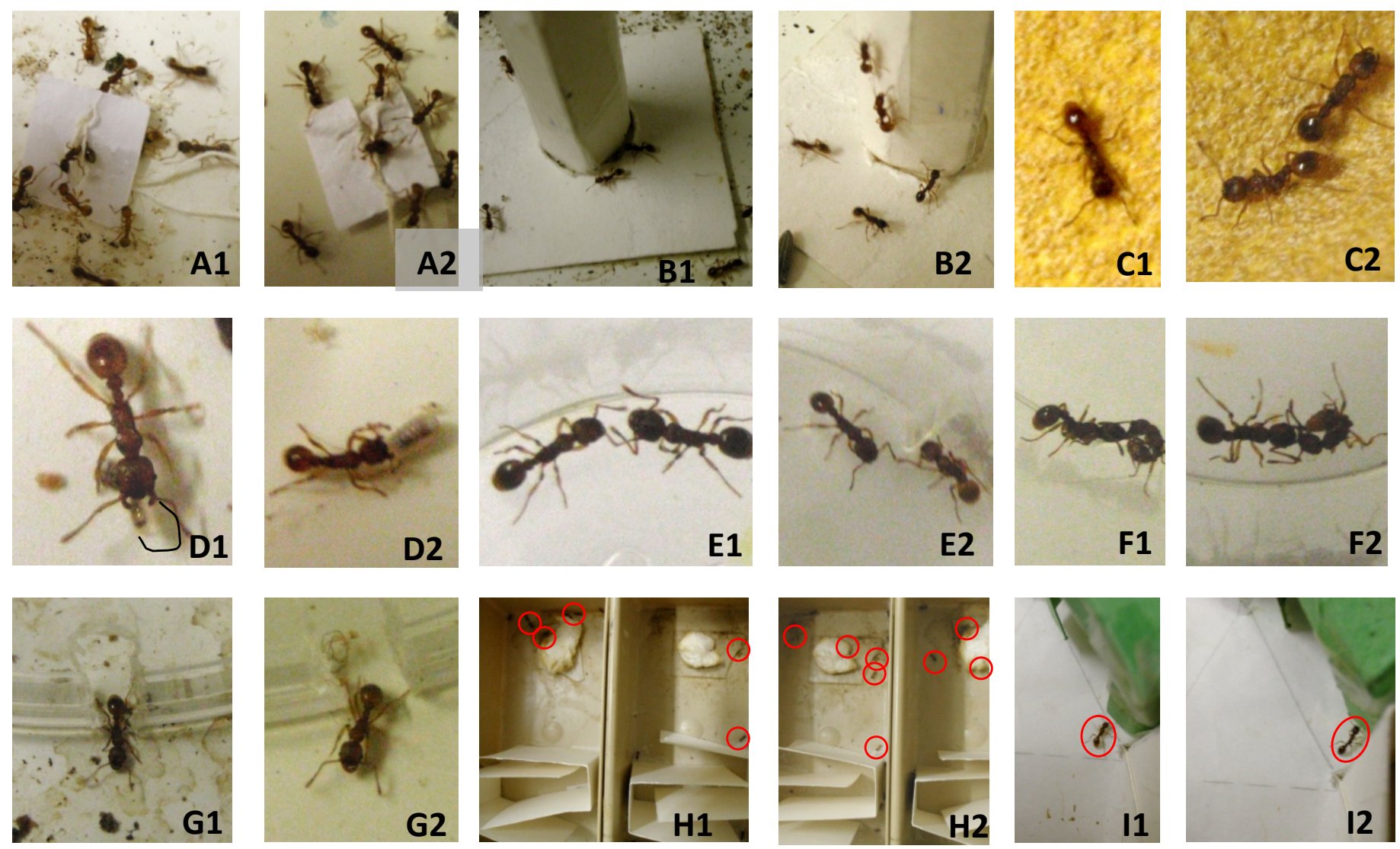

Figure 3. Some views of the experiments relative to lavender odor. 1: Control experiments, without odor; 2: Test experiments, with lavender odor; A: Ants coming towards a tied nestmate and doing so very well under lavender odor; B: Ants coming onto an unknown apparatus and being very numerous in doing so under lavender odor; $\mathbf{C}$ : Ants moving on a rough substrate with difficulty under normal condition as well as under lavender odor (perceiving identically its uncomfortable character); D: Ants taking care of their brood, doing so identically under control condition and lavender odor (NB: D1: the larva has been encircled in black); E: Two nestmates not at all aggressive under normal condition as well as under lavender odor; F: An ant aggressing an alien under control condition and being aggressed by the alien under lavender odor; $\mathbf{G}$ : An ant escaping from an enclosure under control condition as well as lavender odor; H: Five ants (red circles) under control condition and eight ants (red circles) under lavender odor having crossed a twists and turns path; I: An ant (red circle) trained to a hollow green cube giving the correct response during a test in a Y-apparatus provided with this cue in one of its branches (under normal condition as well as under lavender odor) 
So, at that time, flowers of lavender were set on the ants' foraging area, and the ants' conditioning score (thus their short-term memory) was again assessed after 4 hours. Ants presented the unexpected score of $100 \%$ (Table 3) (Figures 3I1 and 3I2). All the tested ants correctly responded. It was really exceptional. However, the difference between the ants' score under normal condition and under lavender odor was not statistically significant: $\chi^{2}=1.45, \mathrm{df}=1,0.20<\mathrm{P}<0.30$. Consequently, lavender odor slightly increased the ants' short memory or at least did not decreased it and acted on another ethological or physiological trait which allowed the ants perfectly responding to the cue to which they had been trained.

\section{Discussion and conclusion}

Aiming to investigate, using ants as model organism, if environmental odors effectively affect individuals' physiology and ethology, we found that onion odor adversely affected these insects' locomotion, orientation ability, audacity, tactile perception, social relationship, state of stress, cognition and memory, while lavender odor favorably affected or unchanged these traits.

The ant M. sabuleti navigates using primarily odorous cues and using visual ones only secondarily [34]. This species is thus very sensitive to odors. It can be presumed that the future new queens, after having been fecundated, search for an adequate place in order to nest (e.g. to found a new colony) using-at least to some extent-some odorant cues and some olfactory stimulus. It is reasonable-in the framework of this hypothesis-that the future queen could have her choice of the best nest place be affected by potentially pleasant, non aggressive odors, or at contrary be repelled by aggressive ones.

As a matter of fact, odors are important not only for M. sabuleti and probably other ant species but also for numerous living animals (e.g. insects (cockroaches, butterflies, ants ...), fishes, mammals (rodents, ungulates, primates including the humans) and plants $[25,35,36]$. Despite this importance of odors for animals and the large amount of works made on this topic [same reference as previously], only very few studies have been made on the impact of added environmental odors on these animals' health, physiology and behavior. Our present work has thus a first interesting result: it reveals that ants, and therefore animals, can be impacted by added, unusual, non natural environmental odors.

Effectively, other researchers, working on other animal than ants, have also pointed out the effect of odors on some physiological and ethological traits. Here are two examples. Bradley and co-authors have clearly shown the anxiolytic effect of lavender odor on gerbils [37], and later on that of rose odor [38]. Many studies have been conducted on humans. Here are six examples. In his review, Nimmermark explains with details that some environmental odors may affect the quality of life, the well-being and the health of exposed individuals, impacting their respiratory system and leading to stress related symptoms among others [39]. Working on 44 human subjects, five co-authors proved that odors emanating from swine operations adversely impacted these residents' mood, leading to more tension, more depression, more anger, less vigor, more tiredness and more confusion than what was presented by control subjects [40]. Affirming that odors perception has emotional correlates in humans, three co-authors examined the impact of such a perception on humans' arousal level and task performance. They effectively showed that the reaction time significantly decreased in ambient odor condition, what-concluded the authors-underlines the importance of the olfactory environment in human behavior [41]. On basis of the fourth example, it should be accepted that some odors undoubtedly affect humans' behavior since they can affect their EEG
[42]. Let us here recall the work of Moss and co-authors [4] cited in the introduction section. It is thus plausible that the use of essential oils through aerial diffusion or direct inhalation could be efficient to some extend (our sixth example) [43]. These six here above reported studies are only six ones among numerous ones revealing impacts of given odors on some humans' traits. Moreover, there exist a large variety of plants which emit several kinds of odors potentially able to act on animals' including humans' health [44]. For instance, several ones emit toxic compounds [45,46] while other ones, as jasmine [47] as well as valerian and passiflora [33] are known to have a calming effect. An important point must be underlined on the basis of the works made by Moss and co-authors [4] on one hand, and those made by Bradley and co-authors [37] as well as us on the other hand. While the former authors found a decrease of cognitive abilities and memory under exposure to essential oil of lavender (a very concentrated product), the latter authors found an improvement of these traits under lavender odor. This means that for aromatherapy, just like for the use of pharmaceutical drugs, the employed concentration must be correctly chosen for obtaining beneficial effects and avoiding harmful ones.

To finish, let us add that, in humans and perhaps also in several animals, the individuals' state of stress (and maybe some other physiological traits state) may influence, and somewhat modify the odor perception [48].

The present topic, i.e. the impact of environmental odors on organisms' health, leads to consider a nowadays increasing event: the air pollution due to humans' activities. If odors impact the organisms' physiology and mood, as shown in the present study, then, the air pollution could become a more severe health problem than just causing respiratory or allergenic problems. Air pollution might also affect humans' and animals' behavior. The atmosphere pollution is presently largely examined, debated, and control solutions are researched (let cite the books of Elson [49] and of Seinfeld and Pandis [50] selected among numerous works of the subject).

To come back to our present work, all the bibliographically found results, cited in the introduction and the discussion section are in agreement with our ones, what seems to indicate that ants can be used as biological models in order to study the potential effect of odors on animals' physiology and ethology. Of course, more researches are needed to refine the model "ant" as response model to odorant stimuli.

A second aim of our study was to check if, effectively, and as objectively as possible (see the introduction section), odors may affect animals' health, including the humans. At this time, and considering that ants constitute a good biological model for most physiological responses to odorant stimuli, our response tended to be affirmative. It can thus be hypothesized that at least some environmental odors affect, positively or negatively, the individuals' health.

In conclusion, environmental odors influence several physiological and ethological traits of an ant species, and could potentially influence major behavioral traits in other animals and humans. If we accept to this point that ants are good biological model for revealing the potential influence of odors on animals' physiology and behavior, we can go a step further, and state that attention should be given to the odors surrounding the humans (adults and children) and the animals: adverse ones should be avoided, favorable ones should be prioritized. Odors should be considered as an important environmental parameter, such like noises [51], temperature, light, and humidity among others. These 
parameters should be chosen or adapted in order to provide to anyone the best possible environment.

\section{Conflict of interest}

We affirm having no conflict of interest concerning the impact on, and the use of odors for, animals and humans. We are independent researchers, working on ants' physiology and ethology, and we receive no money for making our research.

\section{Acknowledgements}

We sincerely thank Mr R. Cammaerts for his valuable advices and help throughout the realization of the present work, the bibliographical research and the writing of the paper. We present our greatest thanks to the Editor of the journal for his excellent work and contact.

\section{References}

1. Lawless H (1991) Effects of odors on mood and behavior: aromatherapy and related effects. In: The human Sense of Smell' Eds Laing DG, Springer-Verlag, Berlin Heidelberg, pp: 361-386.

2. Kadohisa M (2013) Effects of odor on emotion, with implications. Front Syst Neurosci 7: 66

3. Herz R (2009) Aromatherapy facts and fictions: A scientific analysis of olfactory effects on mood, physiology and behavior. Int J Neurosci 119: 263-290. [Crossref]

4. Moss M, Cook J, Wesnes K, Duckett P (2003) Aromas of rosemary and lavender essential oils differentially affect cognition and mood in healthy adults. Intern $J$ Neuroscience 113: 15-38. [Crossref]

5. Lehrner J, Eckersberger C, Walla P, Pötsch G, Deecke L (2000) Ambient odor of orange in a dental office reduces anxiety and improves mood in female patients. Physiol Behav 71: 83-86. [Crossref]

6. Jackson RN (2009) The effect of stimulating and soothing smells on heart rate and memory. McNair Scholars Journal.

7. Cammaerts MC (2018) Physical dependence on a substance occurs when the effect of this substance rapidly decreases after withdrawal. JSM Anat Physiol 3: 1017.

8. Cammaerts MC, Cammaerts D (2015) Physiological and ethological effects of fluoxetine, on ants used as biological models. Int J Biol 7: 1-18.

9. Cammaerts MC, Cammaerts R (2016) Aspartame increases food demand and impacts behavior: A study using ants as models. Acta Biomed Sci. 3: 9-23.

10. Sherwood L, Klandorf H, Yancey P (2016) Physiologie animale. De Boeck superieur Editors, Belgium, pp: 904

11. Bousquet C (2003) Bêtes de science. Seuil, pp: 240

12. Andre RG, Wirtz RA, Das YT (1989) Insect models for biomedical research. In: Woodhead AD, editor. Non-mammalian animal models for biomedical research. CRC Press, Boca Raton, FL, pp: 62-70.

13. Abramson CI, Wells H, Janko B (2007) A social insect model for the study of ethanol induced behavior: the honey bee. In Yoshida, R. (Ed.), Trends in alcohol abuse and alcoholism research. Nova Sciences Publishers pp: 197-218.

14. Hölldobler B, Wilson EO (1990) The ants. Harvard university press, Springer-Verlag: Berlin, pp: 732

15. Passera L, Aron S (2005) Les fourmis: comportement, organisation sociale et évolution. Les Presses Scientifiques du CNRC, Ottawa, Canada, pp: 480.

16. Billen J, Morgan ED (1998) Pheromone communication in social insects - sources and secretions. In: Vander Meer RK, Breed MD, Espelie KE, Winston MLK (editors.), Pheromone Communication in Social Insects: Ants, Wasps, Bees, and Termites; Westview Press: Boulder, Oxford, pp: 3-33.

17. Cammaerts MC, Cammaerts D (2014) Comparative outlook over three Myrmica species' biotopes and foragers' know-how. Biologia 69: 1051-1058.

18. Cammaerts MC, Cammaerts R (2015) Ontogenesis of ants' cognitive abilities (Hymenoptera, Formicidae). Adv Stud Biol 7: 335-348.

19. Cammaerts MC, De Doncker P, Patris X, Bellens F, Rachidi Z, et al. (2012) GSM $900 \mathrm{MHz}$ radiations inhibits ants' association between food sites and encountered cues. Electrom Biol Med 31: 151-165. [Crossref]
20. Cammaerts MC, Rachidi Z, Bellens F, De Doncker P (2013) Food collection and responses to pheromones in an ant species exposed to electromagnetic radiation. Electrom Biol Med 33: 282-288.

21. Cammaerts MC, Cammaerts D (2017) Physiological effects of statines; a study on ants as models. J Pharmac Res Health care 9: 145-157.

22. Cammaerts MC, Cammaerts R (2018) Ethological and physiological effects of the recently most used analgesic, ibuprofen; a study on ants as models. EC Pharmacol Toxicol 6: 251-267.

23. Block E (2010) Garlic and other alliums: the lore and the science. Royal society of chemistry, Cambridge.

24. Brodnitz MH, Pascale JV (1971) Thiopropanal S-oxide: a lachrymatory factor in onions. J Agr Food Chem 19: 269-272.

25. Heldt HW, Piechulla B, Heldt F (2011) Plant biochemistry academic press. Elsevier London, Burlington, San Diego.

26. Willem JP (2002) Les huiles essentielles, médecine d'avenir. Editions du Dauphin, pp $155-157$

27. European medicines agency (EMA), Committee on herbal medicinal product (HMPC) (2012) Assessment report on Lavandula angustifolia Miller, aetheroleum and Lavandula angustifolia Miller, flos.

28. European medicines agency (EMA), Committee on herbal medicinal products (HMPC) (2012) Community herbal monograph on Lavandula angustifolia Miller, flos.

29. Cammaerts MC, Morel F, Martino F, Warzée N (2012) An easy and cheap softwarebased method to assess two-dimensional trajectories parameters. Belg J Zool 142: 145151 .

30. Cammaerts MC, Gosset G, Rachidi Z (2014) Some physiological and ethological effects of nicotine; studies on the ant Myrmica sabuleti as a biological model. Int J Biol 6: 64-81.

31. Siegel S, Castellan NJ (1989) Non-parametric statistics for the behavioral sciences McGraw-Hill Book Company: Singapore, pp: 396.

32. Cammaerts MC, Rachidi Z, Cammaerts R (2016) Physiological and ethological effects of alprazolam, using ants as biological models. WJ Pharmac Sci 4: 474-489.

33. Cammaerts MC, Cammaerts R, Rachidi Z (2016) Effects of four plants extract used as an anxiolytic; a study on ants as models. Adv Biomed Pharm 3: 280-295.

34. Cammaerts MC, Rachidi Z (2009) Olfactory conditioning and use of visual and odorous elements for movement in the ant Myrmica sabuleti (Hymenoptera, Formicidae) Myrmecol News 12: 117-127.

35. Leroy Y (1987) L'univers odorant de l'animal. Socité Nouvelle des Editions Boubée, Paris, pp: 75006.

36. Sauvion N, Calatayud PA, Thiery D, Marion-Poll F (2013) Interactions insectesplantes. Eds Quae + IRD Eds

37. Bradley BF, Starkey NJ, Brown SL, Lea RW (2007) Anxiolytic effects of Lavandula angustifolia odour on the Mongolian gerbil elevated plus maze. J Ethnopharmacol 111 517-525. [Crossref]

38. Bradley BF, Starkey NJ, Brown SL, Lea RW (2007) The effects of prolonged rose odor inhalation in two animal models of anxiety. Physiol Behav 92: 931-938. [Crossref]

39. Nimmermark S (2004) Odour influence on well-being and health with specific focus on animal production emissions. Ann Agricul Environ Med 11: 163-173. [Crossref]

40. Schiffman SS, Sattely EA, Mark M, Brevick SS, Graham G (1995) The effect of environmental odors emanating from commercial swine operations on the mood of nearby residents. Brain Res Bull 37: 369-375.

41. Millot JL, Brand G, Morand N (2002) Effects of ambient odors on reaction time in humans. Neurosci Lett 322: 79-82.

42. Lorig T, Schwartz GE (1988) Brain and odor: I. Alteration of human EEG by odor administration. Psychobiol 16: 281-284.

43. 43 Carsch G (1987) Aromatherapy, a status review and commentary. Soap Cosmet Chem Specialties 88: 36-42.

44. Crozier A, Clifford MN, Ashihara H (2006) Plant secondary metabolites. Occurrence, structure and role in the human diet. Blackwell Publishing Ltd, England, USA, Australia.

45. Engel F, Guillemain J (2003) Plantes irritantes et allergisantes d'appartement et de jardins: Prudence! Ne pas toucher. Ed Institut klorane, 15, rue Théron-Périé 81106 Castres Cedex. 
46. Fourasté I (2001) Plantes toxiques sauvages et horticoles Prudence! Ne pas cueillir Ed Institut klorane, 15, rue Théron-Périé 81106 Castres Cedex.

47. Hossain SJ, Aoshima H, Koda H, Kiso Y (2004) Frangrances in oolong tea that enhance the response of GABBA receptors. Biosci Biotechnol Biochem 68: 1842-1848. [Crossref]

48. Hoenen M, Wolf OT, Bettina M, Pause BM (2017) The impact of stress on odor perception. J Behav Ther Experim Psych 25: 49-69.
49. Elson DM (1992) Atmospheric pollution: a global problem. Blackwell, Oxford. United Kingdom, pp: 34.

50. Seinfeld JH, Pandis SN (2016) Atmospheric chemistry and physics. From air pollution to climate change. Third Edition. Eds J Wiley \& Sons, pp: 1232.

51. Cammaerts MC, Cammaerts D (2018) Impact of environmental noise on insects' physiology and ethology - a study on ants as models. Biol Engin Med 3: 1-8.

Copyright: $\bigcirc 2018$ Cammaerts M. This is an open-access article distributed under the terms of the Creative Commons Attribution License, which permits unrestricted use, distribution, and reproduction in any medium, provided the original author and source are credited. 